\title{
Measuring Cognitive Load in Blended Laboratory Setting: Toward Enhanced Learning in Chemistry
}

\author{
Roselle D. Urbano, Dennis G. Caballes
}

Department of Graduate School, Centro Escolar University, Philippines

\begin{abstract}
The present study explored on the effectiveness of blended laboratory environment in performing activities and it determined whether a significant relationship exists between the cognitive load levels and the enhanced learning of freshman students in Inorganic Chemistry via blended laboratory setting. Freshman students enrolled in Bachelor of Secondary Education $(n=77)$ were the respondents of the study. Seven blended laboratory activities were performed. Pretest and posttest were administered and evaluated and their cognitive loads. The findings showed a significant difference between the pretest and posttest means results of the respondents and these results imply that the students learned conceptually by performing activities using blended laboratory. Among the seven activities performed, only one activity focusing on atomic models has a significant relationship to the performance in Chemistry $(r=0.235)$. This seems to suggest that the more the students were challenged with the situation the better they were able to understand the concept and were able to employ more attention. The results implied that blended laboratory setting can be used as a method in teaching concepts in Inorganic Chemistry to fully optimize more the potential of education technology.
\end{abstract}

Keywords-blended laboratory, cognitive load, enhanced learning.

\section{INTRODUCTION}

Cognitive Load Theory provides a framework that has been used extensively to investigate how learning occurs optimally and reduce of cognitive load.CLT has been described generally as a theory focused on the link between the learner and the material. What has not been examined is how different laboratory setting may affect cognitive load. The laboratory setting environment and how the laboratory activities are performed, should be treated as a separate factors influencing cognitive load. The selection of either virtual or conventional format can affect the overall cognitive load levels (Choi, van Merrienboer, \& Paas, 2014). Additionally, recent work showed that students need an optimal environment to reduce cognitive load levels and increase learning (Shadiev, Hwang, Huang, $\&$ Liu, 2015). The effects of the different laboratory settings need consideration in cognitive load research. Moreover, research supports the concept of examining the physical learning environment as a way to improve learning. Kalyuga and Liu (2015) highlighted CLT as an effective theory of education that has neglected to address the influence the learning environment has on learning.
Besides, there are few researches that have been done comparing how students will learn in different physical learning environments. A focus on the laboratory setting allows future researchers to explore ways that learning can transpire. However, there is a gap in the literature surrounding the correlation of cognitive load levels and students' learning via blended setting of laboratory environment, a hybrid of virtual and conventional laboratory classroom. It was discovered that virtual laboratories are applicable to complete tasks that are not possible to conduct due to lack of resources. It was also indicated that some conventional laboratories should not be forgotten for the reason that hands-on experiences are priceless (Diaz, 2015). In view of these findings the researcher deemed it important to ascertain whether a significant relationship exists between the cognitive load levels and the students' enhanced learning of Inorganic Chemistry via blended laboratory setting.

\section{RESEARCH QUESTIONS}

Specifically, the study sought answers to the following questions: 
1. What were the students' level of understanding in Inorganic Chemistry prior to exposure to blended laboratory setting?

2. Was there a significant difference in the conceptual understanding of the students in Inorganic Chemistry before and after their exposure to blended laboratory setting?

3. Was there a significant correlation between cognitive load levels and students' conceptual understanding of Inorganic Chemistry when exposed to blended laboratory setting?

4. What were the students' learning and teachers' experiences on the use of blended laboratory setting?

\section{LITERATURE REVIEW}

Measuring cognitive load is vital to understanding what causes cognitive load levels for the learner. Cognitive load can be used to measure human cognitive resources needed to complete a task. The results can aid learners not only from identifying load levels but also using the data to prepare them decide on their future course selection decisions (Korbach et al., 2017). Measuring cognitive load levels can be done through the use of several empirical methods such as indirect measurements through task performance, dual task performance, bio-measurements including MRI, and subjective rating scales. While each has benefits, most CLT researchers have focused on the self-rating scales (Leppink \& van den Heuvel, 2015).

To measure cognitive load levels was mentioned in the review of measuring cognitive load done by Brunken, et al. (2010). They specified combined (efficiency) as a wellestablished approach to model the relation between mental effort and performance that has been introduced by Paas and Van Merrienboer (1993).

The measurement of cognitive load is not only significant but it also helps in the understanding of how the physical learning environment affects load levels. With recent changes, adding the physical learning environment as a causal factor to cognitive load, being able to identify and measure cognitive load has become increasingly important (Leppink et al., 2014). The researcher opted to use combined (efficiency) approaches to measure both the mental effort and performance of the subject students that were exposed to blended learning.

Blended learning has become a new form of learning and teaching in science education. Researchers have indicated that the blended learning could create more meaningful environment in learning, support deep-level understanding, and contribute to better learning achievement in the exam (Niroj \& Srisawasdi, 2014).

Blended learning is being described as a way of meeting the challenges of tailoring learning and development to the needs of individuals by integrating the innovative and technological advances in online learning environment (Thorn, 2013).

Research revealed that students who participated in blended learning model could achieve learning outcomes in science than those who participated in the traditional teaching method significantly. In additions, they also found that the students have positive attitude toward science if the learning environment had incorporated internet access. Such, they concluded that the blended learning could be used to overcome the difficulties of practical science (Yapici \& Akbayin, 2012).

Some researchers also explored some of the benefits of using blended learning in higher education institutions. They describe how blended learning has transformative potential, offering institutions the opportunity to embrace technology, encourage a community of inquiry, and support active and meaningful learning (Garrison \& Kanuka, 2014).

Blended learning improves professional development in the education and it has the ability to foster a professional learning community. It allows the development of social cohesion due to the inclusion of a face-to-face component (Owston et al., 2018). Moreover, blended learning also promotes student satisfaction. It enables the students to become more motivated and more involved in the learning process, thereby enhancing their commitment and perseverance (Donnelly, 2010).

Research acknowledged that both virtual laboratory and conventional laboratory have their benefits and disadvantages. Virtual laboratory should not take the place of conventional laboratory, but they should instead complement one another. Further, it was mentioned that science educators should be aware of how virtual laboratories can allow students to complete a laboratory task that would otherwise be missed due to lack of resources. However, it was regarded that educators should remember that some conventional laboratories should not be forgotten because hands-on experience is priceless (Diaz, 2015).

Moreover, the rich combination of both conventional and virtual laboratories provides the best learning environment for students. There may be some instances where carrying out both the virtual and conventional laboratories are the best option. Showing the virtual laboratory first gives students the opportunity to understand what they are 
supposed to see, and then the conventional laboratory provides them the prospect to utilize what they have learned with all of the complexities that come with any real-world issue (Diaz, 2015).

Virtual laboratories allow students opportunities to design and test their own procedures; this is not always possible in a traditional setting. The opportunity to test ideas that might be too expensive or time-consuming to carry out is also a benefit of virtual environment (Gabric et al., 2015).

They also specified that virtual laboratories acknowledge students to engage in the most up-to-date research and experimentation. They discovered that technological tools, such as sensors, provide students with realistic data even if they do not have all of the background knowledge to understand it. A sensor is a device that detects or measures a physical property and records, indicates, or otherwise responds to it. These sensors can measure actual specimens more quickly and accurately than conventional methods. Transferring those data to the computer where the virtual aspect allows students to see what is taking place with the data they collected then provides opportunities for deeper understanding (Gabric et al., 2015).

The researcher had explored and reviewed studies on blended learning being identified as combination of both conventional and virtual laboratories. They provide the best learning environment for students and valued to give desired outcomes in the learning process.

The results showed that utilizing different types of laboratories, teachers have opportunity to change students' perception about why laboratories are useful and can lead the student to be more interested and therefore more engaged.

Studies also show the importance of analyzing the factors influencing cognitive load and learning outcomes. Researches added that Cognitive Load Theory is an important theory of education but neglected to address the relationship between the cognitive load levels and different laboratory setting on the students learning.

Similar with the works of Bowman (2018) where he measured the cognitive load of students but considered physical setting as on-line and traditional classroom, in the present study considered blended learning, which is a hybrid of virtual and conventional laboratory.

Another difference of the study from what have been reviewed is that it measured two aspects of cognitive load, the mental effort and the performance. Most of the reviewed studies concentrated only on measuring one aspect of cognitive load which is the mental effort. The results from the reviewed studies have helped in the present investigation because of the insights provided by the studies.

\section{METHODOLOGY}

This study utilized the quasi-experimental method. Specifically, a pretest-posttest design without a control group was used to determine learning gained in Inorganic Chemistry in blended laboratory setting. The onset of the experimentation was at the beginning of the semester to eliminate the novelty effect, though the actual treatment period where the data gathered was after the preliminary examination administered. The experimentation was applied up to the end of the semester for ethical consideration. A pretest was administered to all respondents prior to the treatment. The pretest was found helpful in gauging students' prior knowledge of chemistry. One of the instruments employed was a fifty-item multiple choice type of Achievement Test developed by the researcher and validated by subject specialists. Reliability test was done through measuring the Cronbach's alpha by administering the achievement test to students $(n=42)$ who were not the respondents of the study. The calculated Cronbach's alpha was found 0.81.To measure the cognitive load, combined or efficiency approach was employed. To measure mental effort, the most widely used measurement of self -rating mental effort formulated by Paas, et. al (2014) was adapted. It measures perceptions of mental effort caused by a task. The internal consistency reliability of the instrument (Cronbach's alpha) was measured and the computed value was $\alpha=0.87$. The blended activities were also validated by experts. It was mentioned by the evaluators that the activities presented were suitable for freshman students who would take up basic chemistry subject. The use of computer simulations was commendable as it facilitated better understanding of rather complex topics in Chemistry. Guide questions helped students in the gradual and more profound understanding of the concepts being tackled.

\section{DISCUSSION}

The conceptual understanding of the students in Inorganic Chemistry prior to exposure to blended laboratory setting was evaluated. The scores of all the respondents $(n=77)$ fall below the half of the total points (50) of the pretest. This seems to imply that the students have weak foundation on selected concepts in Inorganic Chemistry. The results of the analysis also show that there is a significant difference between the performance of the students before and after exposure to blended laboratory setting as reflected from table 1. 
Table.1: Paired Samples t-test Results on the Difference between the Performance of the Students on Pretest and Posttest after Exposure to Blended Laboratory Setting

\begin{tabular}{ccccc}
\hline $\begin{array}{c}\text { Section / } \\
\text { Test } \\
\text { Type }\end{array}$ & t-value & $\begin{array}{c}\text { Sig. } \\
\text { value }\end{array}$ & Interpretation & $\begin{array}{c}\text { Decision } \\
\text { to } \mathrm{H}_{0}\end{array}$ \\
\hline $\begin{array}{c}\text { A } \\
\text { pretest } \\
\text { posttest }\end{array}$ & -14.754 & 0.000 & Significant & Reject \\
B & & & & \\
pretest & -16.223 & 0.000 & Significant & Reject \\
posttest & & & & \\
\hline
\end{tabular}

$\alpha=0.05$ Level of Significance

As it can be gathered from the table that the two sections,

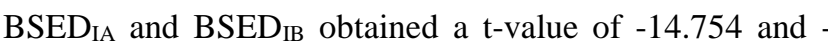
16.223 respectively, with a probability value of 0.000 less than $\alpha=0.05$ that led to the rejection of the null hypothesis that the conceptual understanding of students in Inorganic Chemistry does not differ before and after exposure to blended learning. It shows that there is a significant difference between the pretest and posttest mean results of the respondents. This signifies that the students' learned or gained conceptual understanding in performing activities using blended laboratory setting.

This seems to suggest that students benefitted from the blended setting and gained conceptual understanding through the performance of blended laboratory activities. A significant weak positive correlation between the selfreported mental effort and posttest scores in chemistry was obtained. This can be attributed to the reason that all the students graduated from high school barrios. They seemed to be not acquainted in performing laboratory activities and this can be considered a new experienced for them. The performance of laboratory activities regardless whether virtual or conventional, fostered learnings and positive attitudes among students as have been reflected from their responses. Teachers observed the entire experimental period also expressed positive feedbacks regarding the use of blended laboratory setting.

\section{CONCLUSIONS AND RECOMMENDATIONS}

Based on the findings of the study, the following conclusions were drawn:

1) Students have weak foundation in Inorganic Chemistry.
2) Using blended laboratory setting may cause the significant difference between the performance of the students before and after exposure to it.

3) Revisiting and modifying laboratory activities may ensure that students do not experience cognitive load but instead promote better understanding of the concept discussed from the lecture.

4) Blended laboratory activities foster learnings and developed positive attitudes among students. Teachers observed the potentials of blended laboratory setting to improve the engagement and active participation of students.

In harmony of the findings and conclusions of the study, the following recommendations were proposed for consideration:

1.) Blended laboratory setting can be used as a method in teaching concepts in Inorganic Chemistry such to more fully optimized the potential of education technology.

2.) Parallel studies can be done on other fields of Chemistry such as Advanced Chemistry so as to look the effectiveness of blended learning

3.) A related study can be conducted considering the performance of every activity both in conventional and virtual settings and it is worth to consider also to look on cognitive overload as one of the factors.

4.) Trainings and seminars must be given to teachers to equip and encourage them to engage on the usage of technology in teaching.

\section{ACKNOWLEDGEMENT}

The authors would like to thank their families for the realization of this research.

\section{REFERENCES}

[1] Garrison, D. R., \& Kanuka, H. (2014). Blended learning: uncovering its transformative potential in higher education. The Internet and Higher Education, Vol. 7(2), pp. 95-105.

[2] Hadie, S. N., and Yusoff, M. S. (2016). Assessing the validity of the cognitive load scale in a problembased learning setting. Journal of Taibah University Medical Sciences, Vol. 11(3), pp. 194-202. išpe

[3] Hofstein, A., \& Lunetta, V.N. (2007). The laboratory in science education: the state of the art. Chemistry Education Research and Practice, Vol.8 (2),

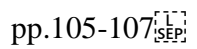

[4] Johnson, A. and Johnson, S. (2009). Learning in the laboratory: some thoughts from the literature. University Chemistry Education, Vol. 5, pp. 42-51. Retrieved 
http://www.rsc.org/images/Vol_5_No2_tcm18-7041.pdf.isep?

[5] Kalyuga, S., \& Liu, T. C. (2015). Guest editorial: managing cognitive load in technology-based learning environments. Educational Technology \& Society, Vol. 18(4), pp. 1-8.

[6] Korbach, A., Brunken, R., \& Park, B. (2017). Differentiating different types of cognitive load: a comparison of different measures. Educational Psychology Review.

[7] Kruger, J., and Doherty, S. (2016). Measuring cognitive load in the presence of educational video: towards a multimodal methodology. Australasian Journal of Educational Technology, vol. 32(6), pp. 19-31.

[8] Kubli, F. (2015). Science teaching as a dialogue- bakhtin, vygotsky and some applications in the classroom Science \& Education, Vol. 14(6), pp. 501- 534.

[9] Lamb, R. (2016). Examination of the effects of dimensionality on cognitive processing in science: A computational modeling experiment comparingonline laboratory simulations and serious educational games. Springer Science

[10] Leppink, J., \& van den Heuvel, A. (2015). The evolution of cognitive load theory and its application to medical education. Perspectives on Medical Education, Vol 4(3), pp. 119-127.

[11] Leppink, J., Paas, F., Gog, T. V., van der Vleuten, C. P., \& van Merrienboer, J. J. (2014). Effects of pairs of problems and examples on task performance and different types of cognitive load. Learning and Instruction, Vol. 30(4), pp.32-42

[12] Luketic, C. D., \& Dolan, E. L. (2013). Factors influencing student perceptions of high-school science laboratory environments. Learning Environments Research, Vol. 16(1), pp. 37-47.

[13] Manor, B., Zhou, J., Jordan, A., Zhang, J., Fang, J., \& Pascual-Leone, A. (2016). $\quad$ Reduction of dual-task costs by noninvasive modulation of prefrontal activity in healthy elders. Journal of Cognitive Neuroscience, Vol. 28(2), pp. 275-281.

[14] Markowitz, D. \& Holt, S. (2011). Simulating science. Science Teacher,Vol. 78(5), pp. 44-48.

[15] Niroj, S., \& Srisawasdi K. (2014). Supporting students' conceptual development of light refraction by simulation-based open inquiry with dual-situated learning model. Journal of Computers in Education, Vol. 1(1), pp. 49-79.

[16] Owston, R., Wideman, H., Murphy, J., \& Lupshenyuk, D. (2018). Blended teacher professional development: A synthesis of three program evaluations. The Internet and Higher Education, Vol. 11(3-4), pp. 201- 210.

[17] Paas, F. G., van Merrienboer, J. J., \& Adam, J. J. (1994). Measurement of cognitive load in instructional research. Perceptual and Motor Skills, Vol. 79(1), pp. 419430.

[18] Paas, F. G., van Merrienboer, J. J., \& Adam, J. J. (1994). Measurement of cognitive load in instructional research. Perceptual and Motor Skills, Vol. 79(1), pp. 419-
430.

[19] Paas, F., \& Ayres, P. (2014) Cognitive load theory: A broader view on the role of memory in learning and education. Educational Psychology Review, Vol.26(1), pp. 191- 195.

[20] Paas, F., Gog, T., \& Sweller, J. (2010). Cognitive load theory: New conceptualizations, specifications, and integrated research perspectives. Educational Psychology Review, Vol. 22(2), pp. 115-121.

[21] Park, B., \& Brunken, R. (2015). The rhythm method: A new method for measuring cognitive load- an experimental dual-task study. Applied Cognitive Psychology, Vol. 29(2), pp. 232-243.

[22] Plass, J.L., \& Leutner, D. (2013). Assessment of cognitive load in multimedia learning using dual-task methodology. Experimental Psychology,Vol. 49(2), pp. 109-119.

[23] Prensky, M. (2012). Teaching digital natives: Partnering for real learning. Science Education, Vol. 94(1), pp. 1-28.

[24] Pyatt, K. \& Sims, R. (2012). Virtual and physical experimentation in inquiry- based science labs: attitudes, performance and access. Journal of Science Education \& Technology, Vol. 21(1), pp. 133147.

[25] Radulovic B.and Stojanovic, M. (2016). The effects of laboratory inquire-based experiments and computer simulations on high school students' performance and cognitive load in physics teaching. IPI ISSN 0579-6431

[26] Schmeck, A., Opfermann, M., Gog, T. V., Paas, F., \& Leutner, D. (2014). Measuring cognitive load with subjective rating scales during problem solving: differences between immediate and delayed ratings. Instructional Science, Vol. 43(1), pp. 93-114.

[27] Shadiev, R., Hwang, W., Huang, Y., \& Liu, T. (2015). The impact of supported and annotated mobile learning on achievement and cognitive load. Educational Technology \& Society, Vol. 18(4), pp. 53-69.

[28] Shields, K., \& Behrman, E. (2011). Children and computer technology: analysis and recommendations. The Future of Children, Vol. 10(2), pp. 4-30.

[29] Stewart, J. \& Vincent, D. (2014). Supercharging lessons with a virtual lab. Science Education, Vol. 97(1), pp. $1-31$.

[30] Sweller, J. (1988). Cognitive load during problem solving: Effects on learning. Cognitive Science, Vol. 12(2), pp. 257-285.

[31] Sweller, J. (2010). Element interactivity and intrinsic, extraneous, and germane cognitive load. Educational Psychology Review, Vol. 22(2), pp. 123-138.

[32] Sweller, J., Ayres, P., \& Kalyuga S. (2011). Cognitive load theory. New York: Springer.

[33] Thorn K. (2013). Exploring problem solving patterns and their impact on learning achievement in a blended learning environment. Computers \& Education, Vol. 56(1), pp.138-145. 